\title{
Molecular Diagnostics of Arthroconidial Yeasts, Frequent Pulmonary Opportunists
}

\author{
Engin Kaplan, ${ }^{a}$ (D) Abdullah M. S. Al-Hatmi, ${ }^{b, c, d, e ~(D) ~ M a c i t ~ I l k i t, ~}{ }^{a}$ A. H. G. Gerrits van den Ende, ${ }^{b}$ (D) Ferry Hagen, ${ }^{e, f}$ \\ (D) Jacques F. Meis, ${ }^{\text {e,f }}$ G. Sybren de Hoog ${ }^{b, c, e}$ \\ aDivision of Mycology, Department of Microbiology, Faculty of Medicine, University of Çukurova, \\ Adana, Turkey \\ bWesterdijk Fungal Biodiversity Institute, Utrecht, the Netherlands \\ Institute of Biodiversity and Ecosystem Dynamics, University of Amsterdam, Amsterdam, the Netherlands \\ dDirectorate General of Health Services, Ibri Hospital, Ministry of Health, Muscat, Oman \\ 'Center of Expertise in Mycology Radboudumc/Canisius-Wilhelmina Hospital (CWZ), Nijmegen, the \\ Netherlands \\ fDepartment of Medical Microbiology and Infectious Diseases, Canisius-Wilhelmina Hospital (CWZ), Nijmegen, \\ the Netherlands
}

ABSTRACT Magnusiomyces capitatus and Saprochaete clavata are members of the clade of arthroconidial yeasts that represent emerging opportunistic pulmonary pathogens in immunocompromised patients. Given that standard ribosomal DNA (rDNA) identification often provides confusing results, in this study, we analyzed 34 isolates with the goal of finding new genetic markers for classification using multilocus sequencing and amplified fragment length polymorphism (AFLP). The interspecific similarity obtained using rDNA markers (the internal transcribed spacer [ITS] and large subunit regions) was in the range of 96 to $99 \%$, whereas that obtained using protein-coding loci (Rbp2, Act, and Tef1 $\alpha$ ) was lower at 89.4 to $95.2 \%$. Ultimately, Rbp2 was selected as the best marker for species distinction. On the basis of cloned ITS data, some strains proved to be misidentified in comparison with the identities obtained with phenotypic characters, protein sequences, and AFLP profiles, indicating that different copies of the ribosomal operon were present in a single species. Antifungal susceptibility testing revealed that voriconazole had the lowest MIC against $M$. capitatus, while amphotericin B had the lowest MIC against S. clavata. Both species exhibited in vitro resistance to fluconazole and micafungin.

KEYWORDS amplified fragment length polymorphism, antifungal, biodiversity, Geotrichum, Magnusiomyces, Saprochaete, Geotrichum, Magnusiomyces, antifungal susceptibility testing

rare he arthroconidial yeast-like fungi Magnusiomyces capitatus and Saprochaete clavata are significant opportunists, causing pulmonary and disseminated infections in patients with acute hematological malignancies and other immune disorders (1-6). Multicenter outbreaks of S. clavata associated with high short-term case fatality rates have been reported in Europe (2). These fungi are classified in the family Dipodascaceae, order Saccharomycetales $(7,8)$, and as such are phylogenetically related to the ascomycetous yeasts, although their thallus is filamentous without budding cells. In culture, both species show relatively expanding, whitish, butyrous colonies (9) with fragmenting hyphae producing arthroconidia and are thermotolerant, with optimum growth occurring at temperatures above $30^{\circ} \mathrm{C}$. The environmental niche of these fungi is as yet unknown, but they were recently discovered to be regular colonizers of household dishwashers (10-12) and have occasionally been found in dairy products

Received 2 September 2017 Returned for modification 2 October 2017 Accepted 18 October 2017

Accepted manuscript posted online 25 October 2017

Citation Kaplan E, Al-Hatmi AMS, Ilkit M, Gerrits van den Ende AHG, Hagen F, Meis JF, de Hoog GS. 2018. Molecular diagnostics of arthroconidial yeasts, frequent pulmonary opportunists. J Clin Microbiol 56:e01427-17. https://doi.org/10.1128/JCM.01427-17.

Editor David W. Warnock

Copyright $\odot 2017$ American Society for Microbiology. All Rights Reserved.

Address correspondence to Macit Ilkit, macitilkit@gmail.com. 
(13). The transmission of S. clavata through contaminated medical devices has also been suggested (2).

M. capitatus and S. clavata are physiologically differentiated by their growth responses to cellobiose, salicin, and arbutin (14) and were reported to show a $4 \%$ difference in their ribosomal DNA (rDNA) internal transcribed spacer (ITS) sequences (7). Despite these differences, misidentifications between the two species are frequent due to conflicting data sets (15). This sheds doubt on the reliability of rDNA ITS regions as markers for discrimination. Therefore, the aim of the present study was to reclassify 34 clinical and environmental isolates from the $M$. capitatus/S. clavata clade using a polyphasic approach. For this purpose, we adopted multilocus sequencing, which has now effectively replaced conventional phenotypic methods for species delimitation. In addition to the rDNA ITS region, we also sequenced the partial large subunit (LSU) rDNA region, as well as the Tef1 $\alpha, R p b 2$, and Act genes. The topologies of the obtained phylogenetic trees were verified by use of the amplified fragment length polymorphism (AFLP) profiles, and the clinical, phenotypic, and antifungal profiles were compared.

Both M. capitatus and S. clavata have undergone several name changes since their first identification, which is largely due to repeated changes in the rules of fungal nomenclature. They were classified in different genera, Saprochaete and Magnusiomyces, upon the discovery of a sexual phase in M. capitatus, at the time when separate names were attributed to fungi with sexual and clonal forms of sporulation (16). However, in 2013, the one fungus, one name principle was adopted (17). This principle abandoned the dual naming system for fungi, and molecular phylogeny became the main criterion for genus delimitation. Further, no reevaluation of the current naming systems has been performed for the genera of arthroconidial yeasts in the Dipodascaceae. Therefore, the present study can help to provide a stable nomenclature for this important group of fungi. In addition, we retested the antifungal susceptibility profiles in order to verify whether any systematic differences are evident in this newly defined group.

\section{MATERIALS AND METHODS}

Isolates. We used 34 isolates from the M. capitatus/S. clavata clade recovered from clinical $(n=19)$, environmental ( $n=14$ ), and unknown $(n=1)$ sources. Detailed strain data are provided in Table 1. Reference strains were obtained from the culture collection of the Centraalbureau voor Schimmelcultures (CBS; housed at the Westerdijk Fungal Biodiversity Institute), Utrecht, the Netherlands. All isolates were subcultured on malt extract agar (MEA; Oxoid, UK) at $25^{\circ} \mathrm{C}$ prior to the experiments.

Physiology. Physiological tests for the utilization of cellobiose, salicin, and arbutin (all from Acros Organics, Morris, NJ, USA) were performed to distinguish the isolates, with glucose assimilation being used as a control $(18,19)$. In brief, inocula were prepared in $5 \mathrm{ml}$ yeast nitrogen base (YNB; BD Difco, Sparks, MD, USA). Tubes were incubated at $24^{\circ} \mathrm{C}$ and shaken for up to 5 days. The effect of temperature on cell growth was verified on MEA at $24^{\circ} \mathrm{C}, 30^{\circ} \mathrm{C}, 37^{\circ} \mathrm{C}, 40^{\circ} \mathrm{C}$, and $45^{\circ} \mathrm{C}$ for up to 1 week.

DNA extraction. Genomic DNA was extracted following the cetyltrimethylammonium bromide (CTAB) protocol (20). The quality of genomic DNA was verified using a NanoDrop 2000 spectrophotometer (Thermo Fisher Scientific, Wilmington, DE, USA). Samples were stored at $-20^{\circ} \mathrm{C}$ until use.

DNA amplification and sequencing. Five gene regions were amplified from the genomic DNA. The primer pairs used are listed in Table 2. PCR mixtures (final volume, $25 \mu \mathrm{l}$ ) contained $10 \times$ PCR buffer ( 2.5 $\mu \mathrm{l}), 1 \mu \mathrm{l}$ of a deoxynucleoside triphosphate mix (10 mM), $1 \mu \mathrm{l}$ of each primer $(10 \mu \mathrm{M})$, Taq polymerase $(5 \mathrm{U} / \mu \mathrm{l})$, template DNA ( $1 \mu \mathrm{l}$ of $100 \mathrm{ng} / \mu \mathrm{l})$, and nuclease-free water. Amplification was performed in an $\mathrm{ABI}$ Prism 2720 thermocycler (Applied Biosystems, Foster City, CA, USA), as follows: $95^{\circ} \mathrm{C}$ for $4 \mathrm{~min}$, followed by 30 cycles of $95^{\circ} \mathrm{C}$ for $45 \mathrm{~s}, 45$ to $51^{\circ} \mathrm{C}$ (according to the primer) for $30 \mathrm{~s}$, and $72^{\circ} \mathrm{C}$ for 1.25 min, with a final incubation at $72^{\circ} \mathrm{C}$ for $8 \mathrm{~min}$. PCR products were visualized on a $1.0 \%$ (wt/vol) agarose gel before sequencing. An $\mathrm{ABI}$ PrismH BigDye Terminator (v.3.0) ready reaction cycle sequencing kit (Applied Biosystems) was used for the sequencing reaction. Sequences were determined with an $A B I$ Prism 3100 genetic analyzer (Applied Biosystems) and the primers listed in Table 2, as follows: 1 min at $95^{\circ} \mathrm{C}$, followed by 30 cycles of $10 \mathrm{~s}$ at $95^{\circ} \mathrm{C}, 5 \mathrm{~s}$ at $50^{\circ} \mathrm{C}$, and $2 \mathrm{~min} 60^{\circ} \mathrm{C}$. The reaction products were purified on Sephadex G-50 fine columns (GE Healthcare Bio-Sciences, Uppsala, Sweden), and the sequencing was done on an $\mathrm{ABI} 3730 \mathrm{XL}$ automatic sequencer (Applied Biosystems).

Cloning and sequencing of the ITS region. Cloning was carried out to verify the presence of multiple rDNA repeats. The ITS region of randomly selected strains, CBS 132760, CBS 139.32, CBS 561.97, and CBS 576.82, was amplified using primers ITS1 and ITS4 and the PCR conditions described above. The amplicons were cloned into the pJET1.2/blunt cloning vector using a CloneJET PCR cloning kit (Thermo Fisher Scientific) according to the manufacturer's instructions. Plasmids were extracted and purified using a plasmid miniprep kit (Qiagen, Hilden, Germany). pJET1.2 primers were used for the insert sequencing. 


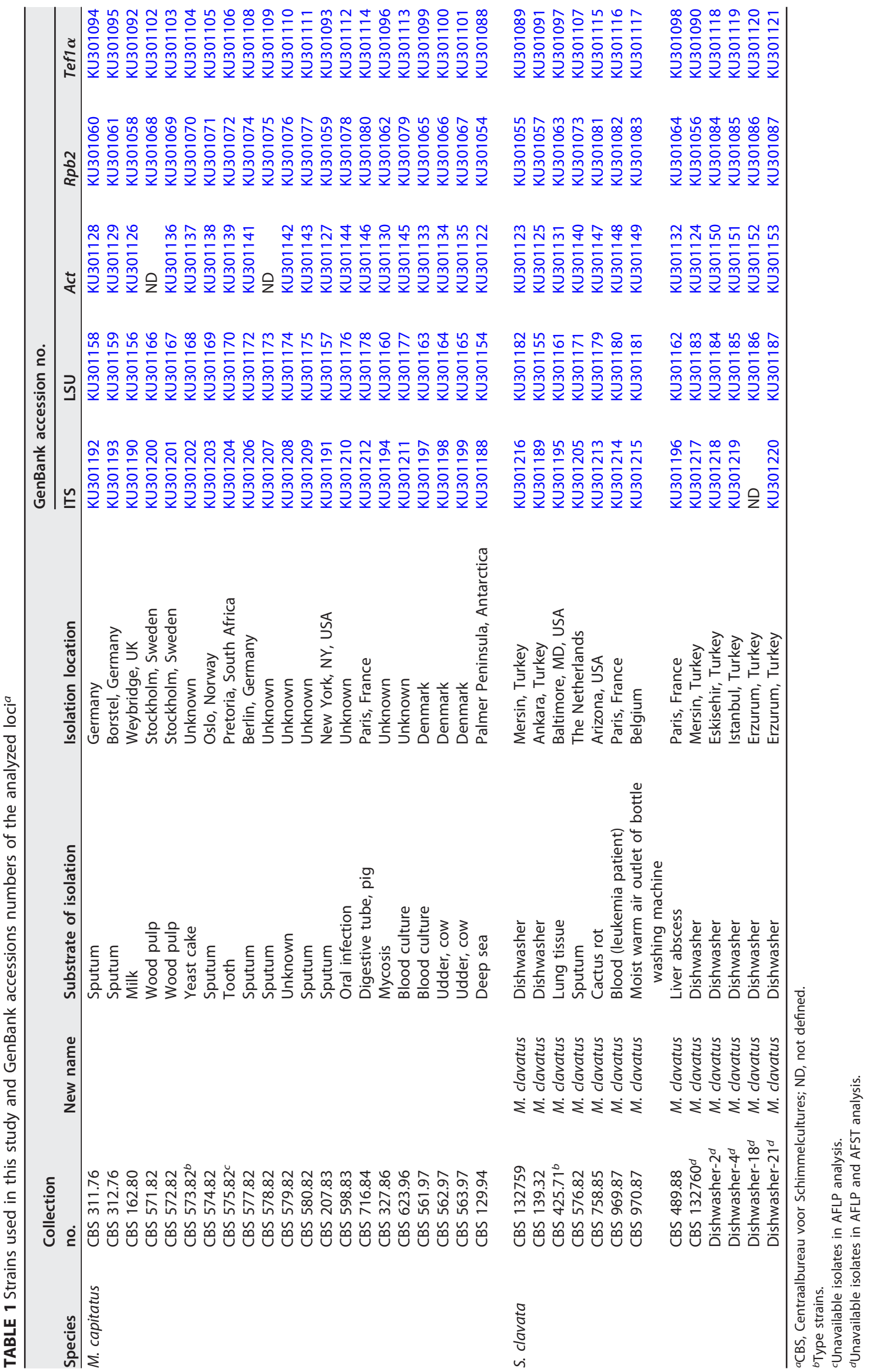


TABLE 2 PCR primers used for amplification

\begin{tabular}{|c|c|c|c|c|c|}
\hline Locus & Product & Primer & Primer sequence $\left(5^{\prime}-3^{\prime}\right)$ & Annealing temp $\left({ }^{\circ} \mathrm{C}\right)$ & Reference \\
\hline ITS & ITS1-5.8S rRNA gene-ITS2 & ITS1 & TCCGTAGGTGAACCTGCGG & 48 & 40 \\
\hline LSU & $\mathrm{D} 1 / \mathrm{D} 2$ & LROR & ACCCGCTGAACTTAAGC & 45 & 41 \\
\hline \multirow[t]{2}{*}{ Rpb2 } & RNA polymerase II & Rpb2-6F & TGGGGKWTGGTYTGYCCTGC & 51 & 43 \\
\hline & & Rpb2-7R & CCCATWGCYTGCTTMCCCAT & & 43 \\
\hline Tef1 $\alpha$ & Translation elongation factor 1 alpha & YTEF-1G & GGTAAGGGTTCTTTCAAGTACGCTTGGG & 51 & 44 \\
\hline Act & & CA5R & GTGAACAATGGATGGACCAGATTCGTCG & & 45 \\
\hline
\end{tabular}

The purified PCR fragments were sequenced on an ABI Prism 3130xl genetic analyzer at MedSanTek Biotechnologies (Istanbul, Turkey). To eliminate the possibility of contamination, repeat PCRs, dual cloning, and sequencing of both directly obtained and cloned amplicons were carried out.

Sequence alignment and phylogenetic analyses. Consensus sequences were analyzed with SeqMan software from the Lasergene package (DNAStar, Madison, WI, USA) and manually edited. Independent alignments and phylogenetic analyses were performed with BioNumerics (v.4.5) software (Applied Maths, Sint-Martens-Latem, Belgium).

AFLP. High-quality genomic DNA was extracted and analyzed by AFLP fingerprinting, as described previously (21). The raw data generated by fragment analysis with the $A B \mid 3500 \times L$ genetic analyzer (Applied Biosystems) were imported into BioNumerics (v.7.6.1) software (Applied Maths), and an unweighted pair group method using average linkages (UPGMA)-based dendrogram was generated by use of the Pearson correlation similarity matrix.

Antifungal susceptibility testing. Determination of the broth dilution MICs of antifungal agents was carried out following the Clinical and Laboratory Standards Institute M27-A3 document (22). The concentration ranges were as follows: 0.016 to $16 \mathrm{mg} /$ liter for amphotericin B (Bristol-Myers Squibb, Woerden, the Netherlands), itraconazole (Janssen Research Foundation, Tilburg, the Netherlands), voriconazole (Pfizer Central, Sandwich, UK), posaconazole (Merck, Whitehouse Station, NJ, USA), and isavuconazole (Basilea Pharmaceuticals, Basel, Switzerland); 0.062 to $64 \mu \mathrm{g} / \mathrm{ml}$ for fluconazole (Pfizer); and 0.008 to $8 \mu \mathrm{g} / \mathrm{ml}$ for anidulafungin (Pfizer) and micafungin (Astellas Pharma Inc., Ibaraki, Japan). After 48 $h$ of incubation at $35^{\circ} \mathrm{C}$, the MIC and minimum effective concentration (MEC) values were determined visually, using a mirror, by comparing the growth in wells containing the drug with that in a drug-free control well. Quality control was performed for every new batch of MIC plates with the following reference strains: Aspergillus flavus ATCC 204304, Candida parapsilosis ATCC 22019, and Candida krusei ATCC 6258. The MICs for all reference strains were within the expected ranges.

\section{RESULTS}

Multilocus sequencing. A preliminary analysis based on the nucleotide sequences of the ITS and LSU loci revealed a close match (96 to $99 \%$ similarity) between $M$. capitatus and S. clavata. Three additional loci, Rpb2, Tef1 $\alpha$, and Act, were sequenced, and a total of 166 new sequences, including 33 ITS, 34 LSU, 32 partial Tef $1 \alpha, 34$ partial $R p b 2$, and 33 partial Act sequences (Table 1), were added to the previously published 22 ITS and 14 LSU sequences from GenBank or the Centraalbureau voor Schimmelcultures genome database (see Table $\mathrm{S} 1$ in the supplemental material). The total lengths of the sequenced ITS, LSU, Tef1 $\alpha$, Rpb2, and Act sites were 348 bp, 597 bp, 628 bp, 708 $\mathrm{bp}$, and $631 \mathrm{bp}$, respectively. Out of the 2,979-bp concatenated sequences for each isolate, 165 nucleotide sites were found to be variable. In interlocus comparisons, Rpb2 had the highest number of variable sites $(n=82,11.5 \%)$. The variable sites of all loci were predominately present as two variants (Table 3 ).

Phylogenetic analyses revealed different abilities of the ITS-based tree and concatenated tree containing LSU, Rbp2, Act, and Tef1 $\alpha$ loci for distinguishing M. capitatus and S. clavata (Fig. 1 and 2). The ITS locus was unable to separate the species because some strains assumed positions that conflicted with the remaining data. However, in the concatenated tree excluding ITS, M. capitatus and S. clavata clearly clustered in two separate groups (Fig. 2), which matched the remaining characteristics analyzed. Consequently, the genetic distance for each locus varied significantly and was the lowest for ITS and LSU and was the highest for Rbp2, Act, and Tef1 $\alpha$. Importantly, Rbp2 was found to be the best marker for reliable discrimination (Table 3).

The positions of the individual strains differed among the obtained trees. Three reference isolates (CBS 132759, CBS 139.32, and CBS 132760) and four nonreference 
TABLE 3 Multilocus sequencing data

\begin{tabular}{|c|c|c|c|c|c|c|c|}
\hline \multirow[b]{3}{*}{ Locus } & \multirow{3}{*}{$\begin{array}{l}\text { No. of isolates } \\
\text { analyzed }\end{array}$} & \multicolumn{6}{|c|}{ No. of sites } \\
\hline & & \multirow[b]{2}{*}{ Total } & \multirow[b]{2}{*}{ Variable } & \multicolumn{4}{|c|}{ Parsimony informative } \\
\hline & & & & Total & Two variants & Three variants & Four variants \\
\hline LSU & 34 & 597 & 4 & 4 & 4 & 0 & 0 \\
\hline $\operatorname{Tef1} \alpha$ & 32 & 628 & 32 & 29 & 29 & 0 & 0 \\
\hline$R p b 2$ & 34 & 708 & 82 & 80 & 79 & 1 & 0 \\
\hline
\end{tabular}

isolates (Dishwasher-2, Dishwasher-4, Dishwasher-18, and Dishwasher-21) of M. capitatus were placed in the same branch with $S$. clavata strains in the concatenated tree. In contrast, 11 M. capitatus strains and 9 strains of S. clavata, including the M. capitatus and S. clavata type strains (CBS 573.82 and CBS 425.71, respectively), showed the same position in the ITS and concatenated trees (Fig. 1 and 2).

Cloning and sequencing of the ITS region. Comparisons of the multiple-sequence alignments of the sequences of the directly sequenced and cloned amplicons of the ITS region revealed some variable nucleotides and insertions/deletions in the cloned strains, especially in ITS2. Two strains, CBS 576.82 and CBS 139.32, changed position at the species level in the ITS tree when the data for the cloned and directly sequenced amplicons were compared (Fig. 1). Such heterogeneity in the ITS region indicated the possibility of different copies of rDNA within the ribosomal operon of selected strains.

AFLP. The AFLP profiles contained approximately 50 to 60 fragments that were 40 to $400 \mathrm{bp}$ long. The AFLP dendrogram comprised two main clusters at the species level (M. capitatus, 20 strains; S. clavata, 6 strains). The majority of the M. capitatus and S. clavata strains were divided into two main clusters, which corresponded to their division in the multilocus tree. However, two strains of M. capitatus (CBS 139.32 and CBS 132759) were found in the opposite cluster. On the basis of the placement of strains in the clusters, no clear demarcation according to sample origin (e.g., clinical or environmental) or geographic location was evident (Fig. 3).

Physiology. The ability of all strains to assimilate cellobiose, salicin, and arbutin was evaluated. All strains of $S$. clavata could assimilate all of these carbon sources, unlike many $M$. capitatus isolates. However, six isolates of $M$. capitatus (as defined by the ITS sequence data) showed growth on these carbon sources; these were the same isolates that clustered as S. clavata strains in the concatenated tree. All M. capitatus and S. clavata isolates were able to grow at $30^{\circ} \mathrm{C}, 37^{\circ} \mathrm{C}$, and $40^{\circ} \mathrm{C}$; no growth of $M$. capitatus isolates was observed at $45^{\circ} \mathrm{C}$, but the $S$. clavata isolates showed limited growth at this temperature. All S. clavata isolates grew robustly after transfer from $45^{\circ} \mathrm{C}$ to $25^{\circ} \mathrm{C}$; however, the $M$. capitatus isolates were not viable when they were incubated at $25^{\circ} \mathrm{C}$ after preincubation at $45^{\circ} \mathrm{C}$ (Table 4 ).

Antifungal susceptibility. The geometric mean (GM) MIC or MEC ranges of eight antifungal drugs are summarized in Table 5. Both tested species showed high MIC or MEC values for fluconazole and micafungin ( 8 to 32 and 2 to $>8 \mu \mathrm{g} / \mathrm{ml}$, respectively). The MIC values for $M$. capitatus were in the range of 0.063 to $1 \mu \mathrm{g} / \mathrm{ml}$ for amphotericin $\mathrm{B}$ and isavuconazole; 0.125 to $0.5 \mu \mathrm{g} / \mathrm{ml}$ for itraconazole, voriconazole, and posaconazole; and 2 to $4 \mu \mathrm{g} / \mathrm{ml}$ for anidulafungin. For S. clavata isolates, the MICs were in the range of 0.125 to $0.5 \mu \mathrm{g} / \mathrm{ml}$ for amphotericin $\mathrm{B}, 0.25$ to $0.5 \mu \mathrm{g} / \mathrm{ml}$ for itraconazole, 0.063 to $0.5 \mu \mathrm{g} / \mathrm{ml}$ for voriconazole, $0.25 \mu \mathrm{g} / \mathrm{ml}$ for posaconazole, 0.125 to $1 \mu \mathrm{g} / \mathrm{ml}$ for isavuconazole, and $2 \mu \mathrm{g} / \mathrm{ml}$ for anidulafungin (Table S2).

We further evaluated whether the MIC/MEC values correlated among the strains of M. capitatus and S. clavata (defined by multilocus analysis) using the Mann-WhitneyWilcoxon test for a skewed distribution. At an alpha value of $\leq 0.05$, for all $M$. capitatus isolates, the lowest GM MIC was observed for voriconazole $(0.18 \mu \mathrm{g} / \mathrm{ml})$, followed by posaconazole $(0.24 \mu \mathrm{g} / \mathrm{ml})$, amphotericin B $(0.32 \mu \mathrm{g} / \mathrm{ml})$, and isavuconazole $(0.34$ 


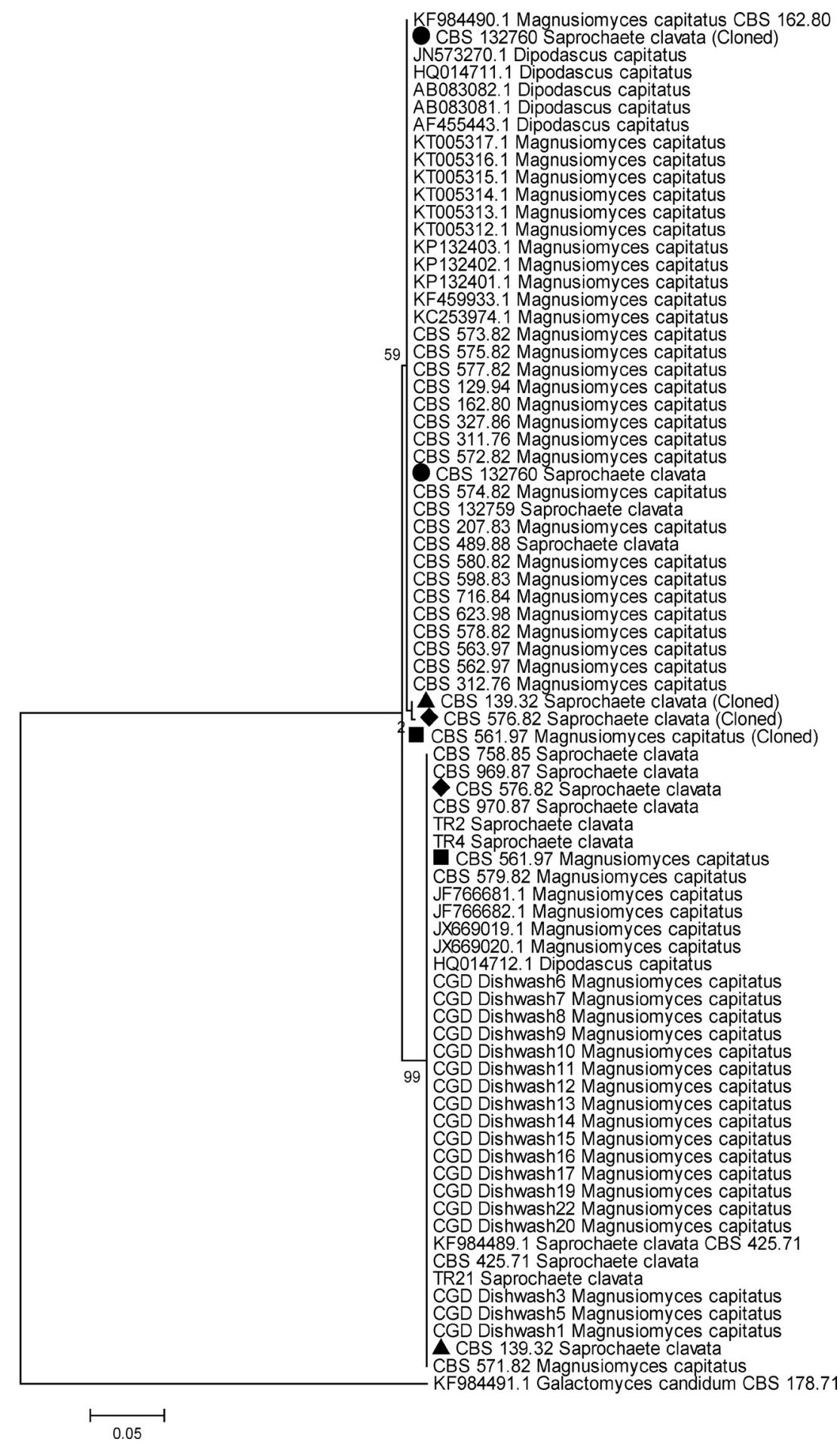

FIG 1 Dendrogram showing the phylogenetic relationships among all 73 isolates. The dendrogram was generated from the ITS regions of $M$. capitatus and S. clavata using the maximum-likelihood method. The Kimura 2-parameter model was used as the substitution model with the gamma correction and 1,000 bootstrap replicates. Values show bootstrap support of $>70 \%$. Strains that were both cloned and directly sequenced are identified by use of the same symbols in the tree.

$\mu \mathrm{g} / \mathrm{ml})$. For all S. clavata isolates, the lowest GM MIC was observed for amphotericin B $(0.22 \mu \mathrm{g} / \mathrm{ml})$, followed by voriconazole and posaconazole $(0.25 \mu \mathrm{g} / \mathrm{ml})$ and then itraconazole $(0.27 \mu \mathrm{g} / \mathrm{ml})$. In contrast, the GM MIC of fluconazole was $19 \mu \mathrm{g} / \mathrm{ml}$ for $S$. clavata and $12.28 \mu \mathrm{g} / \mathrm{ml}$ for M. capitatus. Both species had high MICs of fluconazole and 


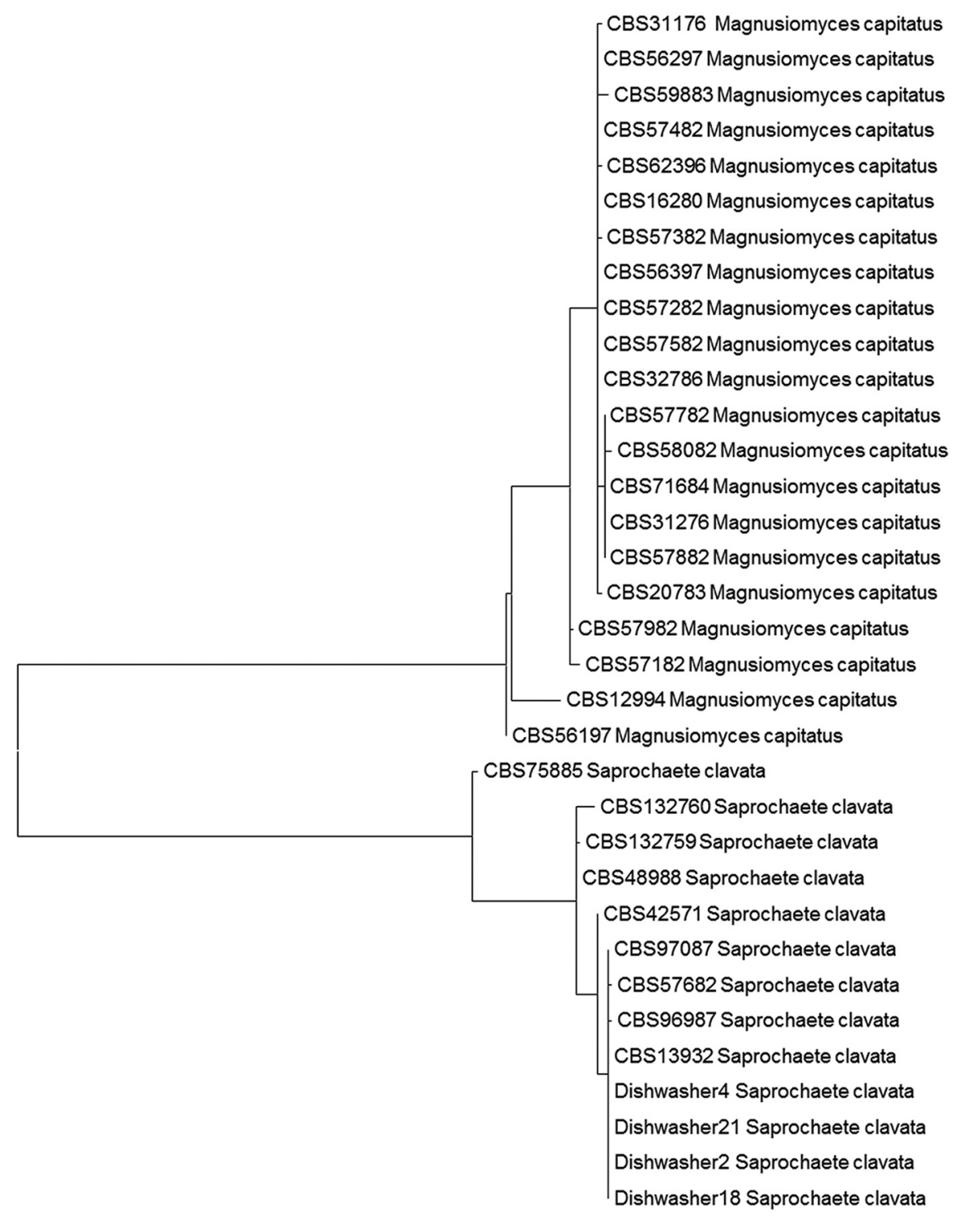

0.0100

FIG 2 Concatenated tree of LSU, Rbp2, Act, and Tef1 $\alpha$ sequences ( $n=34)$. The dendrogram was generated using the maximum-likelihood method. The Kimura 2-parameter model was used as the substitution model with the gamma correction and 1,000 bootstrap replicates. Values show bootstrap support of $>70 \%$.

micafungin; however, no clear specificity of resistance related to sample origin was observed.

\section{DISCUSSION}

The two opportunistic arthroconidial yeasts analyzed in this study were originally described in the genus Geotrichum and were distinguished only on the basis of morphological differences: Geotrichum capitatum exhibited sympodial conidium production, in addition to arthroconidia, while G. clavatum had arthroconidia only. This difference was further supplemented by characterization of physiological parameters (8). However, as larger sets of strains were analyzed, it became clear that classification according to conidial pleomorphism did not always match molecular data. Using D1/D2 LSU data, the species were considered conspecific, as they showed $99 \%$ similarity (23), but subsequent ITS sequence analysis revealed that the species were unambiguously different (7). At the 


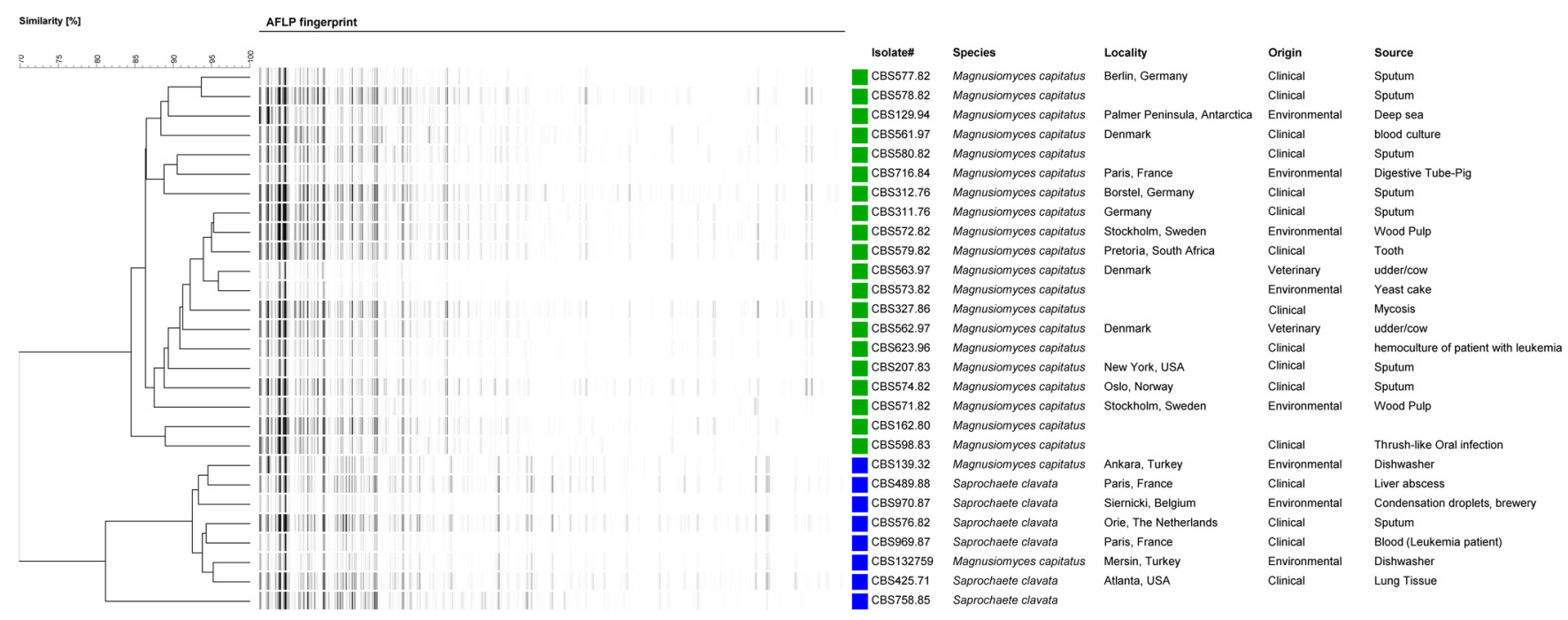

FIG 3 Comparative UPGMA dendrogram of AFLP fingerprints of $M$. capitatus and S. clavata strains.

beginning of the ITS1 locus, the species differ in five positions, whereas in ITS2, there were four deletions and one single nucleotide polymorphism observed in G. capitatum. These differences between the two species were reconfirmed in most of the strains analyzed with an extended data set in the present study, which allowed the reevaluation of current species delimitations by the incorporation of multilocus sequencing data. Although the ribosomal sequence data showed that the species were 96 to $99 \%$ similar, partial sequences of Rbp2, Act, and Tef1 $\alpha$ showed significant and consistent similarities of 89.4 to $95.2 \%$. The initial physiological difference between the two species in response to arbutin, cellobiose, and salicin appeared to be completely consistent with these data. In contrast, the absence of sympodial propagation as a diagnostic criterion appeared to have been based on results for too few strains, as this character was found to be randomly distributed among the strains analyzed in the present study.

Some strains assumed a position in the ITS species tree opposite that obtained using physiology and multilocus sequence data. Maintaining the general consensus of a rate of $1 \%$ ITS sequence divergence to be considered different species (24), the $4 \%$ divergence rate identified in our study cannot be accepted as a reliable threshold for species differentiation for this group. Intraspecies and intragenomic heterogeneities involving the ITS region are based on the presence of multiple intragenomic rDNA copies that show sequence variation. Although this is not uncommon in fungi, when the ratios are close to $50 \%$, amplification results may vary stochastically. A similar situation was documented in another member of the filamentous Saccharomycetales, Geotrichum candidum (25). Indels found in multiple-sequence alignment comparisons of direct and cloned amplicons from the rDNA of strains CBS 576.82 and CBS 139.32 were sufficiently different to position them in either M. capitatus or S. clavata.

The nomenclatural rules and recommendations for fungi have changed several times during the last few decades. In their phylogenetic overview of the Dipodascaceae,

TABLE 4 Carbon assimilation and growth characteristics of $M$. capitatus and S. clavata isolates at various temperatures

\begin{tabular}{|c|c|c|c|c|c|c|c|c|}
\hline \multirow[b]{3}{*}{ Species } & \multicolumn{8}{|c|}{ No. of isolates growing under the following conditions: } \\
\hline & \multicolumn{3}{|c|}{ Carbon source } & \multicolumn{5}{|c|}{ Temp $\left({ }^{\circ} \mathrm{C}\right)$} \\
\hline & Cellobiose & Salicin & Arbutin & 30 & 37 & 40 & 45 & 45 to $25^{a}$ \\
\hline M. capitatus $(n=21)$ & 0 & 0 & 0 & 21 & 21 & 21 & 0 & 0 \\
\hline S. clavata $(n=13)$ & 13 & 13 & 13 & 13 & 13 & 13 & 11 & 13 \\
\hline
\end{tabular}

${ }^{a}$ All S. clavata isolates grew robustly after transfer from $45^{\circ} \mathrm{C}$ to $25^{\circ} \mathrm{C}$. 
TABLE 5 GM MIC or MEC and MIC or MEC ranges of amphotericin B, fluconazole, itraconazole, voriconazole, posaconazole, isavuconazole, anidulafungin, and micafungin for strains of M. capitatus and S. clavata

\begin{tabular}{|c|c|c|c|c|c|c|c|c|c|c|c|c|c|c|c|c|}
\hline \multirow[b]{4}{*}{ Species } & \multicolumn{16}{|c|}{$\mathrm{MIC}^{a}(\mu \mathrm{g} / \mathrm{ml})$} \\
\hline & \multicolumn{2}{|l|}{ AMB } & \multicolumn{2}{|l|}{ FLU } & \multicolumn{2}{|l|}{ ITC } & \multicolumn{2}{|l|}{ VRC } & \multicolumn{2}{|l|}{ POS } & \multicolumn{2}{|l|}{ ISAV } & \multicolumn{2}{|l|}{ AFG } & \multicolumn{2}{|l|}{ MFG } \\
\hline & \multicolumn{2}{|c|}{ MIC ( $\mu \mathrm{g} / \mathrm{ml})$} & \multicolumn{2}{|c|}{ MIC ( $\mu \mathrm{g} / \mathrm{ml})$} & \multicolumn{2}{|c|}{ MIC ( $\mu \mathrm{g} / \mathrm{ml})$} & \multicolumn{2}{|c|}{ MIC $(\mu \mathrm{g} / \mathrm{ml})$} & \multicolumn{2}{|c|}{ MIC $(\mu \mathrm{g} / \mathrm{ml})$} & \multicolumn{2}{|c|}{ MIC $(\mu \mathrm{g} / \mathrm{ml})$} & \multicolumn{2}{|c|}{$\begin{array}{l}\text { MEC } \\
(\mu \mathrm{g} / \mathrm{ml})\end{array}$} & \multicolumn{2}{|c|}{$\begin{array}{l}\text { MEC } \\
(\mu \mathrm{g} / \mathrm{ml})\end{array}$} \\
\hline & Range & GM & Range & GM & Range & GM & Range & GM & Range & GM & Range & GM & Range & GM & Range & GM \\
\hline M. capitatus $(n=21)$ & $0.063-1$ & 0.32 & $8-32$ & 12.28 & $0.125-0.5$ & 0.28 & $0.125-0.5$ & 0.18 & $0.125-0.5$ & 0.24 & $0.063-1$ & 0.34 & $2-4$ & 2.4 & $2->8$ & 6.6 \\
\hline S. clavata $(n=8)$ & $0.125-0.5$ & 0.22 & $16-32$ & 19 & $0.25-0.5$ & 0.27 & $0.063-0.5$ & 0.25 & 0.25 & 0.25 & $0.125-1$ & 0.54 & 2 & 2 & $4-8$ & 6.7 \\
\hline
\end{tabular}

a MICs were determined according to CLSI methods after $48 \mathrm{~h}$ of incubation at $35^{\circ} \mathrm{C}$. AMB, amphotericin B; FLU, fluconazole; ITC, itraconazole; VRC, voriconazole; POS, posaconazole; ISAV, isavuconazole; AFG, anidulafungin; MFG, micafungin; GM, geometric mean; MEC, minimum effective concentration.

de Hoog and Smith (7) noted that Geotrichum was remote as a member of the Endomycetaceae. Indeed, with phylogenetic analysis, the classification of Geotrichum could not be maintained for these fungi. At that time, fungi were subjected to a dual nomenclature system in which sexual and nonsexual forms were attributed to separate genera. For that reason, the two former Geotrichum species were reclassified in different genera, with one, i.e., Magnusiomyces, being defined by the sexual form of propagation, while Saprochaete was used when the form of propagation was unknown. In 2013, the principle of dual nomenclature was abandoned (17), with the oldest name for a fungus having priority and covering all forms of propagation of the fungus. Molecular phylogeny was recommended as the main parameter of classification. Judging by the ribosomal phylogenetic data provided by de Hoog and Smith (7) and confirmed by subsequent studies (15), the genera Magnusiomyces and Saprochaete appear to belong to the same clade, with the caveat that the type species of Saprochaete, Saprochaete saccharophila, has not yet been sequenced and thus might be unrelated. Magnusiomyces, with the type species Magnusiomyces magnusii, is the oldest name for the clade containing the two species under study. The name dates back to Zender (1925); however, Endyllium Clements (1931), Saprochaete Coker \& Shanor ex D.T.S. Wagner \& Dawes (1970), Zendera Redhead \& Malloch (1977), Ascotrichosporon Kocková-Krachovílová et al. (1977), and Blastoschizomyces Salkin et al. (1985) are probably younger synonyms, depending on the final phylogenetic position of their type species. As a consequence, the name S. clavata will have to be changed again, as follows (see page 57 in reference 8): Magnusiomyces clavatus (de Hoog, M.Th. Smith \& Guého) E. Kaplan, comb. nov. Basionym: Geotrichum clavatum de Hoog, M.Th. Smith \& Guého.

Among deposits in databases that had been identified on the basis of morphology or ITS sequences, several misidentifications were revealed in the present study. Judging from the multilocus sequencing data based on the Rbp2, Act, and Tef1 $\alpha$ sequences combined with the ITS sequences, three M. clavatus reference isolates (CBS 132759, CBS 139.32, and CBS 132760) were incorrectly attributed to M. capitatus. This was also confirmed by physiological tests. $M$. capitatus is consistently unable to grow with arbutin, cellobiose, and salicin and does not tolerate a temperature of $45^{\circ} \mathrm{C}$ (Table 3 ). Routine identification of $M$. capitatus with commercially available carbon assimilation tests and automated platforms (e.g., the API 20C AUX, ID 32C, and RapID Yeast Plus systems) is currently not possible because the specific discriminative carbon sources salicin and arbutin are not incorporated in those tests $(8,15)$. Matrix-assisted laser desorption ionization-time of flight mass spectrometry may aid in diagnosis after further expansion of the fungal mass spectrometry profile database $(15,26)$.

Intraspecific variability was particularly evident from the AFLP data. Notably, $M$. clavatus clustered in a single AFLP group (Fig. 3), with two main sublineages containing three and four strains. Further, CBS 758.85 was not part of the sublineages in the $M$. clavatus cluster, which is consistent with the concatenated tree (Fig. 2). Despite the small number of $M$. clavatus strains analyzed in the current study, the AFLP pattern represented these previously reported two main sublineages. On the basis of the 
multilocus dendrogram, $M$. capitatus was found to be more genetically monomorphic than it was by AFLP analysis. Eleven strains of $M$. capitatus and nine strains of $M$. clavatus, including the type strains, showed the same position in the concatenated tree after multilocus analysis, suggesting a possible clonal relationship; however, lower similarities (80 to $90 \%$ ) were observed among the strains of $M$. capitatus after AFLP analysis.

Vaux et al. (2) assessed the genomic single nucleotide polymorphisms of $73 \mathrm{~S}$. clavata isolates using a mapping approach and obtained two largely homogeneous phylogenetic sublineages. In a recent study, Koç et al. (27) evaluated clinical isolates of $M$. capitatus using repetitive element sequence-based-PCR fingerprinting. On the basis of cluster similarity percentages, five main clones were detected; however, no genetic relationship was observed according to the patients' identity, location, or sample type. In addition, Subramanya Supram et al. (28) investigated seven M. capitatus isolates by AFLP genotyping and found $\sim 80 \%$ similarity among these isolates, which was consistent with our findings by AFLP analysis.

Although Vaux et al. (2) referred to two subgroups of $M$. clavatus with different virulence, no correspondence of subgroups with the source or transmission route could be identified, which is in agreement with the findings published in the literature (28-30). Notably, M. capitatus is the main clinical species, while M. clavatus is more frequently encountered in the drawers of household dishwashers. This matches the observed differences in the thermotolerance between the species. It is remarkable that even the slight difference in ecology between these closely related species would lead to such a large clinical difference, given the overall rarity of $M$. clavatus in clinical settings (30). The source and transmission of the main opportunist, $M$. capitatus, are currently unknown and thus need to be clarified.

M. capitatus is mainly known to come from compromised human hosts. The most common risk factor for invasive Magnusiomyces infection is prolonged neutropenia with a poor outcome, and the main portal of entrance is the lung (see Table S3 in the supplemental material) (1,30). A recent cohort study reported a rate of Magnusiomyces sp. infection of 3.4 per 100,000 patients with cancer (31), and household dishwashers have been reported to be an environmental habitat (10-12). This environment combines high temperatures and moisture and provides an indoor reservoir for other waterborne opportunists, such as Candida parapsilosis and Exophiala dermatitidis, which are not commonly isolated from environmental sources. A direct link between susceptible patients and dishwashers has not been established and is perhaps less likely because the immunocompromised host population is mostly hospitalized and thus not directly exposed to household utensils.

Optimal antifungal therapy has not yet been established for infections by $M$. capitatus and M. clavatus. Arendrup et al. (32) recommended amphotericin B (with or without flucytosine) or voriconazole for the treatment of $M$. capitatus infections, but no guideline was reported for M. clavatus. Durán-Graeff et al. (30) noted that echinocandins are not an option for the treatment of infections caused by these arthroconidial yeasts. This situation highlights an urgent need for the identification of optimal treatment parameters for the filamentous yeasts. The present study presents the results of susceptibility testing for one of the largest series of these species to be tested, with susceptibility to eight antifungals being evaluated. Although clinical breakpoints are not available for $M$. capitatus, antifungal susceptibility testing of new isolates is highly recommended (28). Importantly, $M$. capitatus is considered intrinsically resistant to echinocandins $(4,32,33)$. In this study, amphotericin B and triazoles (except for fluconazole) showed potent in vitro activity against $M$. capitatus. This confirms the data available in the literature, which show that itraconazole, voriconazole, and posaconazole (MIC ranges, 0.12 to $0.5,0.25$ to 0.5 , and 0.03 to $0.5 \mu \mathrm{g} / \mathrm{ml}$, respectively $[4,28$, 34-36]) have low MICs against M. capitatus but not fluconazole (MIC range, 16 to 32 $\mu \mathrm{g} / \mathrm{ml}[4,34,36,37])$. In contrast, a study from Nepal demonstrated low MIC values for fluconazole $(2 \mu \mathrm{g} / \mathrm{ml})$ and high MIC values for amphotericin B $(2 \mu \mathrm{g} / \mathrm{ml})$ in seven $M$. capitatus isolates (28). 
Amphotericin B is the most active drug against $M$. clavatus isolates, followed by voriconazole, posaconazole, and itraconazole. Consistent with our findings, fluconazole $(8 \mu \mathrm{g} / \mathrm{ml}$ ) was shown to have poor in vitro activity (38). Favre et al. (39) observed high MEC/MIC values for echinocandins (caspofungin and micafungin) and fluconazole ( $\geq 4 \mu \mathrm{g} / \mathrm{ml}$ and $32 \mu \mathrm{g} / \mathrm{ml}$, respectively), whereas lower MIC values were observed for amphotericin B $(0.25 \mu \mathrm{g} / \mathrm{ml})$, flucytosine $(0.25 \mu \mathrm{g} / \mathrm{ml})$, and both voriconazole and posaconazole $(0.5 \mu \mathrm{g} / \mathrm{ml})$. A recent study also examined the susceptibility profiles of $11 \mathrm{M}$. capitatus and $4 \mathrm{M}$. clavatus isolates using Etest or the Sensititre YeastOne system (30). Overall, the lowest MICs were obtained for triazoles, except fluconazole $(<1 \mu \mathrm{g} / \mathrm{ml}$ for voriconazole, itraconazole, and posaconazole, respectively), followed by flucytosine and amphotericin B. In general, Magnusiomyces species had high MICs for echinocandins, particularly for caspofungin (>32 $\mu \mathrm{g} / \mathrm{ml})$ (30).

In conclusion, we have provided detailed molecular characteristics of two species of arthroconidial yeasts, thereby greatly expanding the current database beyond rDNA ITS sequence classification and incorporating new identification markers obtained using multilocus sequence typing of various genes, such as $R b p 2$. Moreover, antifungal testing revealed that voriconazole and amphotericin $B$ are the most effective against these potential pathogens. Finally, based on our results, we suggest modifying the nomenclature of $S$. clavata according to updated fungal nomenclature guidelines.

\section{SUPPLEMENTAL MATERIAL}

Supplemental material for this article may be found at https://doi.org/10.1128/JCM .01427-17.

SUPPLEMENTAL FILE 1, PDF file, 0.5 MB.

\section{ACKNOWLEDGMENTS}

We are grateful to Ilse Curfs-Breuker for technical assistance.

Engin Kaplan, a Ph.D. student at Çukurova University, Turkey, was supported by a grant from the Federation of European Microbiological Societies (FEMS-RG-2015-0049).

The funders had no influence on the study design; collection, analysis, and interpretation of data; preparation of the manuscript; or decision to publish.

J.F.M. received grants from Astellas, Basilea, and Merck. He has been a consultant to Astellas and Merck and received speakers' fees from Gilead Sciences, Merck, Pfizer, and United Medical. None of the other authors have competing interests.

\section{REFERENCES}

1. Garcia-Ruiz JC, López-Soria L, Olazábal I, Amutio E, Arrieta-Aguirre I, Velasco-Benito V, Pontón J, Moragues MD. 2013. Invasive infections caused by Saprochaete capitata in patients with haematological malignancies: report of five cases and review of the antifungal therapy. Rev Iberoam Micol 30:248-255. https://doi.org/10.1016/j.riam.2013.02 .004 .

2. Vaux S, Criscuolo A, Desnos-Ollivier M, Diancourt L, Tarnaud C, Vandenbogaert M, Brisse S, Coignard B, Dromer F, Geotrichum Investigation Group. 2014. Multicenter outbreak of infections by Saprochaete clavata, an unrecognized opportunistic fungal pathogen. mBio 5:e02309-14. https://doi.org/10.1128/mBio.02309-14.

3. Mazzocato S, Marchionni E, Fothergill AW, Sutton DA, Staffolani S, Gesuita R, Skrami E, Fiorentini A, Manso E, Barchiesi F. 2015. Epidemiology and outcome of systemic infections due to Saprochaete capitata: case report and review of the literature. Infection 43:211-215. https:// doi.org/10.1007/s15010-014-0668-3.

4. Schuermans C, van Bergen M, Coorevits L, Verhaegen J, Lagrou K, Surmont I, Jeurissen A. 2011. Breakthrough Saprochaete capitata infections in patients receiving echinocandins: case report and review of the literature. Med Mycol 49:414-418. https://doi.org/10.3109/13693786 .2010.535179.

5. Birrenbach T, Bertschy S, Aebersold F, Mueller NJ, Achermann Y, Muehle- thaler K, Zimmerli S. 2012. Emergence of Blastoschizomyces capitatus yeast infections, Central Europe. Emerg Infect Dis 18:98-101. https://doi .org/10.3201/eid1801.111192.

6. Saghrouni F, Abdeljelil JB, Youssef YB, Abdeljelil NB, Gheith S, Fathallah A, Said MB. 2012. Geotrichum capitatum septicemia in patients with acute myeloid leukemia. Report of three cases. Med Mycol Case Rep 1:88-90. https://doi.org/10.1016/j.mmcr.2012.09.003.

7. de Hoog GS, Smith MT. 2004. The ribosomal gene phylogeny and species delimitation in Geotrichum and its teleomorphs. Stud Mycol 50:489-515

8. de Hoog GS, Smith MT, Guého E. 1986. A revision of the genus Geotrichum and its teleomorphs. Stud Mycol 29:1-131.

9. de Hoog GS, Guarro J, Figueras MJ, Gené J. 2014. Atlas of clinical fungi: the ultimate benchtool for diagnostics, 4th ed. CD-ROM. CBS-KNAW Fungal Biodiversity Centre, Utrecht, the Netherlands, and Universitat Rovira i Virgili, Reus, Spain.

10. Zalar P, Novak M, de Hoog GS, Gunde-Cimerman N. 2011. Dishwashers-a man-made ecological niche accommodating human opportunistic fungal pathogens. Fungal Biol 115:997-1007. https://doi.org/10.1016/ j.funbio.2011.04.007.

11. Döğen A, Kaplan E, Öksüz Z, Serin MS, Ilkit M, de Hoog GS. 2013. Dishwashers are a major source of human opportunistic yeast-like fungi 
in indoor environments in Mersin, Turkey. Med Mycol 51:493-498. https://doi.org/10.3109/13693786.2012.738313.

12. Gümral R, Özhak-Baysan B, Tümgör $A$, Saraçlı MA, Yıldıran ŞT, Ilkit M, Zupančič J, Novak-Babič M, Gunde-Cimerman N, Zalar P, de Hoog GS. 2016. Dishwashers provide a selective extreme environment for humanopportunistic yeast-like fungi. Fungal Diversity 76:1-9. https://doi.org/ 10.1007/s13225-015-0327-8.

13. Gurgui M, Sanchez F, March F, Lopez-Contreras J, Martino R, Cotura A, Galvez ML, Roig C, Coll P. 2011. Nosocomial outbreak of Blastoschizomyces capitatus associated with contaminated milk in a haematological unit. J Hosp Infect 78:274-278. https://doi.org/10.1016/j.jhin.2011.01.027.

14. Guého E, de Hoog GS, Smith MT, Meyer SA. 1987. DNA relatedness, taxonomy, and medical significance of Geotrichum capitatum. J Clin Microbiol 25:1191-1194.

15. Desnos-Ollivier M, Blanc C, Garcia-Hermoso D, Hoinard D, Alanio A, Dromer F. 2014. Misidentification of Saprochaete clavata as Magnusiomyces capitatus in clinical isolates: utility of internal transcribed spacer sequencing and matrix-assisted laser desorption ionization-time of flight mass spectrometry and importance of reliable databases. J Clin Microbiol 52:2196-2198. https://doi.org/10.1128/JCM.00039-14.

16. Geiser DM, Aoki T, Bacon CW, Baker SE, Bhattacharyya MK, Brandt ME, Brown DW, Burgess LW, Chulze S, Coleman JJ, Correll JC, Covert SF, Crous PW, Cuomo CA, De Hoog GS, Di Pietro A, Elmer WH, Epstein L, Frandsen RJ, Freeman S, Gagkaeva T, Glenn AE, Gordon TR, Gregory NF, HammondKosack KE, Hanson LE, Jímenez-Gasco MDM, Kang S, Kistler HC, Kuldau GA, Leslie JF, Logrieco A, Lu G, Lysøe E, Ma LJ, McCormick SP, Migheli Q, Moretti A, Munaut F, O'Donnell K, Pfenning L, Ploetz RC, Proctor RH, Rehner SA, Robert VA, Rooney AP, Bin Salleh B, Scandiani MM, Scaufblaire J, Short DP, et al. 2013. One fungus, one name: defining the genus Fusarium in a scientifically robust way that preserves longstanding use. Phytopathology 103:400-408. https://doi.org/10.1094/PHYTO-07-12-0150-LE.

17. Hawksworth DL, Crous PW, Redhead SA, Reynolds DR, Samson RA, Seifert KA, Taylor JW, Wingfield MJ, Abaci O, Aime C, Asan A, Bai FY, de Beer ZW, Begerow D, Berikten D, Boekhout T, Buchanan PK, Burgess T, Buzina W, Cai L, Cannon PF, Crane JL, Damm U, Daniel HM, van Diepeningen AD, Druzhinina I, Dyer PS, Eberhardt U, Fell JW, Frisvad JC, Geiser DM, Geml J, Glienke C, Gräfenhan T, Groenewald JZ, Groenewald M, de Gruyter J, Guého-Kellermann E, Guo LD, Hibbett DS, Hong SB, de Hoog GS, Houbraken J, Huhndorf SM, Hyde KD, Ismail A, Johnston PR, Kadaifciler DG, Kirk PM, Kõljalg U, et al. 2011. The Amsterdam Declaration on Fungal Nomenclature. IMA Fungus 2:105-112.

18. Kurtzman CP, Fell JW, Boekhout T, Robert V. 2011. Methods for isolation, phenotypic characterization and maintenance of yeasts, p 87-110. In Kurtzman CP, Fell JW, Boekhout T (ed), The yeasts, a taxonomic study, 5th ed. Elsevier, Amsterdam, the Netherlands.

19. Yarrow D. 1998. Methods for the isolation, maintenance and identification of yeasts, p 77-110. In Kurtzman CP, Fell JW (ed), The yeasts, a taxonomic study, 4th ed. Elsevier, Amsterdam, the Netherlands.

20. Al-Hatmi AM, Bonifaz A, de Hoog GS, Vazquez-Maya L, Garcia-Carmona K, Meis JF, van Diepeningen AD. 2014. Keratitis by Fusarium temperatum, a novel opportunist. BMC Infect Dis 14:588. https://doi.org/10.1186/ s12879-014-0588-y.

21. Hagen F, Jensen RH, Meis JF, Arendrup MC. 2016. Molecular epidemiology and in vitro antifungal susceptibility testing of 108 clinical Cryptococcus neoformans sensu lato and Cryptococcus gattii sensu lato isolates from Denmark. Mycoses 59:576-584. https://doi.org/10.1111/myc.12507.

22. Clinical and Laboratory Standards Institute. 2008. Reference method for broth dilution antifungal susceptibility testing of yeasts; approved standard, 3rd ed; CLSI document M27-A3. Clinical and Laboratory Standards Institute, Wayne, PA.

23. Phaff HJ, Blue J, Hagler AN, Kurtzman CP. 1997. Dipodascus starmeri sp. nov., a new species of yeast occurring in cactus necroses. Int J Syst Bacteriol 47:307-312. https://doi.org/10.1099/00207713-47-2-307.

24. Yurkov A, Guerreiro MA, Sharma L, Carvalho C, Fonseca Á. 2015. Multigene assessment of the species boundaries and sexual status of the basidiomycetous yeasts Cryptococcus flavescens and C. terrestris (Tremellales). PLoS One 10:e0120400. https://doi.org/10.1371/journal.pone.0120400.

25. Alper I, Frenette M, Labrie S. 2011. Ribosomal DNA polymorphisms in the yeast Geotrichum candidum. Fungal Biol 115:1259-1269. https://doi.org/ 10.1016/j.funbio.2011.09.002.

26. Kolecka A, Khayhan K, Groenewald M, Theelen B, Arabatzis M, Velegraki A, Kostrzewa M, Mares M, Taj-Aldeen SJ, Boekhout T. 2013. Identification of medically relevant species of arthroconidial yeasts by use of matrix-assisted laser desorption ionization-time of flight mass spectrometry. J Clin Microbiol 51:2491-2500. https://doi.org/10.1128/JCM.00470-13.

27. Koç AN, Atalay MA, Timur D, Demir G, Kaynar L. 2016. Molecular epidemiology and antifungal susceptibility of Saprochaete capitata (Blastoschizomyces capitatus) isolates causing nosocomial infection in Kayseri/Turkey. Infect Dis (Lond) 48:596-603. https://doi.org/10.1080/23744235.2016.1176246.

28. Subramanya Supram H, Gokhale S, Chakrabarti A, Rudramurthy SM, Gupta S, Honnavar P. 2016. Emergence of Magnusiomyces capitatus infections in western Nepal. Med Mycol 54:103-110. https://doi.org/10 $.1093 / \mathrm{mmy} / \mathrm{myv} 075$.

29. Del Principe MI, Sarmati L, Cefalo M, Fontana C, de Santis G, Buccisano F, Maurillo $L$, de Bellis $E$, Postorino M, Sconocchia G, del Poeta G, Sanguinetti M, Amadori S, Pagano L, Venditti A. 2016. A cluster of Geotrichum clavatum (Saprochaete clavata) infection in haematological patients: a first Italian report and review of literature. Mycoses 59: 594-601. https://doi.org/10.1111/myc.12508.

30. Durán Graeff L, Seidel D, Vehreschild MJ, Hamprecht A, Kindo A, Racil Z, Demeter J, de Hoog S, Aurbach U, Ziegler M, Wisplinghoff H, Cornely OA FungiScope Group. 2017. Invasive infections due to Saprochaete and Geotrichum species: report of 23 cases from the FungiScope Registry. Mycoses 60:273-279. https://doi.org/10.1111/myc.12595.

31. Cornely OA, Gachot B, Akan H, Bassetti M, Uzun O, Kibbler C, Marchetti O, de Burghgraeve P, Ramadan S, Pylkkanen L, Ameye L, Paesmans M, Donnelly JP, EORTC Infectious Diseases Group. 2015. Epidemiology and outcome of fungemia in a cancer cohort of the Infectious Diseases Group (IDG) of the European Organization for Research and Treatment of Cancer (EORTC 65031). Clin Infect Dis 61:324-331. https://doi.org/10.1093/cid/civ293.

32. Arendrup MC, Boekhout T, Akova M, Meis JF, Cornely OA, Lortholary O, European Society of Clinical Microbiology and Infectious Diseases Fungal Infection Study Group, European Confederation of Medical Mycology. 2014. ESCMID and ECMM joint clinical guidelines for the diagnosis and management of rare invasive yeast infections. Clin Microbiol Infect 20:76-98. https://doi.org/10.1111/1469-0691.12360.

33. Chittick P, Palavecino EL, Delashmitt B, Evans J, Peacock JE. 2009. Case of fatal Blastoschizomyces capitatus infection occurring in a patient receiving empiric micafungin therapy. Antimicrob Agents Chemother 53:5306-5307. https://doi.org/10.1128/AAC.00710-09.

34. Martino R, Salavert M, Parody R, Tomás JF, de la Cámara R, Vázquez L, Jarque I, Prieto E, Sastre JL, Gadea I, Pemán J, Sierra J. 2004. Blastoschizomyces capitatus infection in patients with leukemia: report of 26 cases. Clin Infect Dis 38:335-341. https://doi.org/10.1086/380643.

35. D’Antonio D, Mazzoni A, lacone A, Violante B, Capuani MA, Schioppa F, Romano F. 1996. Emergence of fluconazole-resistant strains of Blastoschizomyces capitatus causing nosocomial infections in cancer patients. J Clin Microbiol 34:753-755.

36. Girmenia C, Pizzarelli G, D'Antonio D, Cristini F, Martino P. 2003. In vitro susceptibility testing of Geotrichum capitatum: comparison of the E-test, disk diffusion, and Sensititre colorimetric methods with the NCCLS M27-A2 broth microdilution reference method. Antimicrob Agents Chemother 47: 3985-3988. https://doi.org/10.1128/AAC.47.12.3985-3988.2003.

37. Fernández-Ruiz M, Guinea J, Puig-Asensio M, Zaragoza Ó, Almirante $B$, Cuenca-Estrella M, Aguado JM, CANDIPOP Project, GEIH-GEMICOMED (SEIMC), REIPI. 2017. Fungemia due to rare opportunistic yeasts: data from a population-based surveillance in Spain. Med Mycol 55:125-136. https://doi.org/10.1093/mmy/myw055.

38. de Almeida JN, Jr, Sztajnbok J, da Silva AR, Jr, Vieira VA, Galastri AL, Bissoli L, Litvinov N, Del Negro GM, Motta AL, Rossi F, Benard G. 2016. Rapid identification of moulds and arthroconidial yeasts from positive blood cultures by MALDI-TOF mass spectrometry. Med Mycol 54: 885-889. https://doi.org/10.1093/mmy/myw044.

39. Favre S, Rougeron A, Levoir L, Pérard B, Milpied N, Accoceberry I, Gabriel F, Vigouroux S. 2016. Saprochaete clavata invasive infection in a patient with severe aplastic anemia: efficacy of voriconazole and liposomal amphotericin $B$ with adjuvant granulocyte transfusions before neutrophil recovery following allogeneic bone marrow transplantation. Med Mycol Case Rep 11:21-23. https://doi.org/10.1016/j.mmcr.2016.03.001.

40. White TJ, Bruns T, Lee S, Taylor J. 1990. Amplification and direct sequencing of fungal ribosomal RNA genes for phylogenetics, p 315-322. In Innis MA, Gelfand DH, Sninsky JJ, White TJ (ed), PCR protocols: a guide to methods and applications. Academic Press, San Diego, CA.

41. Rehner SA, Samuels GJ. 1994. Taxonomy and phylogeny of Gliocladium analyzed from nuclear large subunit ribosomal DNA sequences. Mycol Res 98:625-634. https://doi.org/10.1016/S0953-7562(09)80409-7.

42. Vilgalys R, Hester M. 1990. Rapid genetic identification and mapping 
of enzymatically amplified ribosomal DNA from several Cryptococcus species. J Bacteriol 172:4238-4246. https://doi.org/10.1128/jb.172.8 .4238-4246.1990.

43. Liu YL, Whelen S, Hall BD. 1999. Phylogenetic relationships among ascomycetes: evidence from an RNA polymerase II subunit. Mol Biol Evol 16:1799-1808. https://doi.org/10.1093/oxfordjournals.molbev.a026092.

44. Kurtzman CP, Robnett CJ. 2003. Phylogenetic relationships among yeasts of the 'Saccharomyces complex' determined from multigene sequence analyses. FEMS Yeast Res 3:417-432. https://doi.org/10.1016/ S1567-1356(03)00012-6.

45. Daniel HM, Sorrell TC, Meyer W. 2001. Partial sequence analysis of the actin gene and its potential for studying the phylogeny of Candida species and their teleomorphs. Int J Syst Evol Microbiol 51:1593-1606. https://doi.org/10.1099/00207713-51-4-1593. 